\title{
Elevated nitrite in breath condensates of children with respiratory disease
}

\author{
W. Formanek*,+, D. Inci*, R.P. Lauener", J.H. Wildhaber*, U. Frey ", G.L. Hall*,
} Elevated nitrite in breath condensates of children with respiratory disease.
W. Formanek, D. Inci, R.P. Lauener, J.H. Wildhaber, U. Frey, G.L. Hall.
C)ERS Journals Ltd 2002.
ABSTRACT: The aim of the study was to determine the differences in nitrite, in the exhaled breath condensates of healthy children and those children with asthma, cystic fibrosis (CF) and nonasthmatic, episodic cough.

Breath condensates were obtained from 66 children ( 43 males: 23 females, 3.1-16 yrs) and included 29 asthmatics, 12 clinically stable CF patients, 12 children with cough but not asthma and 13 healthy volunteers. The collected condensate was assayed colourimetrically using the Griess reaction to determine nitrite concentrations.

Patients with CF (median: 5-95\% percentiles; 2.02: 0.43-6.37 $\mu \mathrm{M}$ ) or asthma (2.10: $0.63-5.45 \mu \mathrm{M})$ had significantly higher levels of nitrite compared to healthy subjects $(0.41$ : $0.13-1.83 \mu \mathrm{M} ; \mathrm{p}<0.05)$ or subjects with cough $(0.75: 0.03-1.75 \mu \mathrm{M}$; $\mathbf{p}<\mathbf{0 . 0 5})$.

Airway inflammation, as assessed by the nitrite in breath condensates, is present in children with asthma and cystic fibrosis, but not those children with nonasthmatic, episodic cough. Nitrite can be conveniently, cheaply and rapidly measured in breath condensates of children as young as 3 yrs of age, and may prove useful for the assessment of airway inflammation in children with respiratory disease. Eur Respir J 2002; 19: 487-491.

\begin{abstract}
*Swiss Paediatric Respiratory Physiology Research Group, Dept of Respiratory Medicine and \# Division of Immunology, University Children's Hospital, Zürich, and "Dept of Respiratory Medicine, University Children's Hospital, Bern, Switzerland. ${ }^{+}$Wilhelminenspital der Stadt Wien, Austria.
\end{abstract}

Correspondence: G. Hall, Respiratory Medicine, Princess Margaret Hospital for Children, GPO Box D184, Perth, 6840, Australia.

Fax: 61893408181

Keywords: Airway inflammation, breath condensates, children, nitric oxide, respiratory disease

Received: December 12000

Accepted after revision October 17 2001

This study was supported by NH and MRC (Australia), Swiss CF Foundation, AstraZeneca (Switzerland), Swiss National Research Foundation. W. Formanek was subsidized by a grant from the Ärzteverein Wilhelminenspital, Vienna.
Nitric oxide (NO) is a ubiquitous chemical found throughout the body and within the respiratory system. It is thought to be involved in a number of processes, including repair, vasodilation and inflammation [1]. Exhaled nitric oxide (eNO) is raised in asthmatic patients and is reduced following the administration of anti-inflammatories [2]. This elevation is thought to result from the upregulation of inducible NO synthase [3]. Initial expectations were that the NO pathway would be upregulated in patients with cystic fibrosis (CF). Surprisingly, lower $[4,5]$ or similar [6] oral eNO values in $\mathrm{CF}$ patients compared with healthy controls have been reported. The most likely reason for this discrepancy is a decrease in diffusion of NO across secretions of increased viscosity and volume in the airways of CF patients, leading to the formation of nitrite and nitrate. The recent reports that nitrite and nitrate, the metabolites of $\mathrm{NO}$, are increased in $\mathrm{CF}$ patients confirm these theories $[6,7]$.

While the elevation of NO is well recognized in asthmatic patients, the role of NO in those patients with cough or wheeze due to viral or other influences is not well understood. BARALDI et al. [8] demonstrated that eNO was normal in a group of infants after a single wheezy episode due to viral infection. It may be that the measurement of eNO, in those patients with unconfirmed asthma, will allow the discrimination of asthmatic patients and those patients with respiratory symptoms not related to asthma. Indeed the release of recommendations for the standardization of the measurement of eNO in adults and older children $[9,10]$ is likely to result in the adoption of eNO as a diagnostic marker of airway inflammation.

The measurement of eNO involves the patient maintaining a constant expiratory flow against an external resistance, and infants and young children may be unable to perform these manoeuvres. Subglottic gas is saturated with water and the measurement of proteins and lipid mediators in the condensate of the exhaled breath is well recognized [11]. The measurement of nitrites in the breath condensate may allow the implementation of a simple, noninvasive, inexpensive test for the determination of airway inflammation in a paediatric population, and may have a number of advantages over eNO. The same 
test could be applied across all age ranges, allowing serial monitoring of airway inflammation. Nitrites in condensates may also be used in those children with $\mathrm{CF}$, thus allowing laboratories to use a single test for monitoring airway inflammation within all patient groups.

To the best of the authors knowledge, no studies have examined the nitrite levels in children with respiratory diseases other than $\mathrm{CF}$, such as asthma. A study was carried out to measure the nitrites in the breath condensate of children both with and without respiratory disease. The aim of this study was to assess the differences in nitrites in the breath condensate of healthy children and those children with respiratory disease, including asthma, nonasthmatic episodic cough and $\mathrm{CF}$.

\section{Methods}

\section{Subjects}

Sixty-six subjects were enrolled in the study. The subjects were recruited from outpatient clinics at the University Children's Hospital, Zürich, Switzerland. Anthropometric and clinical data are presented in table 1. Children, whom presented with clinical features of an infection of the upper airways were excluded from the study. A detailed history and physical examination were obtained in all children enrolled in the study by the same investigator. Written informed consent was obtained from all parents. The study was approved by the ethics committee of the University Children's Hospital, Zürich. Subjects were recruited to the study if they could be categorized into one of the following four groups.

Group 1: healthy controls. Thirteen subjects (eight male) aged $9.51 \pm 0.98$ yrs (mean \pm SEM) were recruited from nonrespiratory outpatient clinics. These subjects had no parentally reported respiratory complaints or allergic disease, and had no airway obstruction upon physical examination prior to condensate collection. Lung function or allergy tests were not available nor sought in this subject group.

Group 2: episodic cough. Twelve subjects with a history of cough $(n=6)$ and/or wheeze $(n=6)$ at a frequency of $<3$ episodes per yr of life were recruited. These children (seven male) aged 3.08-9.50 yrs $(6.04 \pm 0.55$ yrs) had a normal physical examination when studied. Positive atopic status was found in four subjects (positive skinprick test or radioallergosorbent test (RAST) class 3-6

Table 1.-Patient information and nitrite levels

\begin{tabular}{lcrrr}
\hline $\begin{array}{l}\text { Patient } \\
\text { group }\end{array}$ & $\begin{array}{c}\text { Patient } \\
\mathrm{n}\end{array}$ & $\begin{array}{c}\text { Sex } \\
(\mathrm{M}: \mathrm{F})\end{array}$ & $\begin{array}{c}\text { Age yrs } \\
\text { mean } \pm \text { SEM }\end{array}$ & $\begin{array}{c}\text { Nitrite } \mu \mathrm{M} \text { median } \\
(5-95 \% \text { percentiles })\end{array}$ \\
\hline Healthy & 13 & $8: 5$ & $9.51 \pm 3.53$ & $0.41(0.13-1.83)$ \\
Cough & 12 & $7: 5$ & $6.04 \pm 1.90$ & $0.75(0.03-1.75)$ \\
Asthma & 29 & $21: 8$ & $9.33 \pm 2.95$ & $2.10(0.63-5.45)$ \\
CF & 12 & $7: 5$ & $12.51 \pm 2.60$ & $2.02(0.43-6.37)$ \\
\hline
\end{tabular}

M: male; F: female; CF: cystic fibrosis. for at least one of the tested allergens), while three patients were nonatopic. Atopic status could not be determined in the remaining five children. Four children were being treated with inhaled corticosteroids with the remainder being untreated. These children were classified as nonasthmatic using current clinical guidelines [12].

Group 3: asthmatic children. Twenty-nine asthmatic subjects (21 male) aged 4.4-15.8 (9.33 \pm 0.55$)$ yrs attending respiratory or allergy outpatient clinics were studied. The majority of children $(n=25)$ were asymptomatic at the time of testing, with the remainder $(n=4)$ exhibiting signs of airflow obstruction upon physical examination. The diagnosis of asthma was based on current clinical guidelines [12], such that all children had symptoms of recurrent episodic wheezing, cough and dyspnoea $>3$ times a year. In 13 children, lung function results were available (forced expiratory volume in one second $(\mathrm{FEV} 1)=78.8 \pm 5.9 \%$ predicted $)$. Twenty-five children were classified as mild asthmatics with the remaining four children classified as moderate asthmatics [12]. Atopic status was confirmed in 28 children (26 atopic) by skin-prick test or RAST (class 3-6). Twenty-two children were receiving inhaled corticosteroid treatment.

Group 4: cystic fibrosis. Twelve children with stable CF

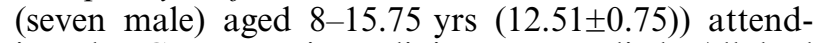
ing the $\mathrm{CF}$ outpatient clinic were studied. All had confirmed CF by sweat test and (with one exception) chromosome mutation analysis. Lung function was available in all but one child. Four children had FEV $1<40 \%$ pred, one exhibited $\mathrm{FEV}_{1<50 \%}$ pred, while two children had an FEV $1<80 \%$ pred, with the remaining children having normal lung function. Seven patients had a confirmed allergy test with only one subject being atopic. No allergy tests were available for the remaining five children. Two children were receiving anti-inflammatory medication.

\section{Study design}

Breath condensates were collected using an adaptation of the method used by DoHLman et al. [13]. Briefly, the subject breathes quietly via a mouthpiece, which included a saliva trap and one-way valve, into a polyvinyl chloride tube $(55 \mathrm{~cm}$ in length and $1 \mathrm{~cm}$ internal diameter), which was passed through a section of pipe packed with ice. The apparatus had an expiratory resistance of $4-5 \mathrm{~cm} \mathrm{H}_{2} \mathrm{O}$ within the flow ranges measured. The children were asked to breathe at a normal frequency and tidal volume, and swallow any saliva. This yielded $0.5-1 \mathrm{~mL}$ of breath condensate over a period of 4-15 min.

\section{Measurement of nitrite}

The nitrite levels in the breath condensates were quantified on standard curves, using the Griess assay. Within 15 min of taking the samples, $250 \mu \mathrm{L}$ of breath condensate was reacted with $250 \mu \mathrm{L}$ of Griess reagent 
$(0.1 \%$ naphthylethylenediamine-dihydrochloride, $1 \%$ sulphanilamide, $3 \% \quad \mathrm{H}_{3} \mathrm{PO}_{4}$ ), and measured at an absorbance wavelength of 550 and $570 \mathrm{~nm}$ with a microplate reader (Model EL 312; BioTek Instruments Inc., Winooski, VT, USA).

\section{Statistics}

Data are presented as median and $5-95 \%$ percentiles as nitrite levels were not normally distributed. Statistical analyses were performed on the log (base 10) nitrite concentrations allowing parametric tests to be performed. A one-way analysis of variance (ANOVA) was used to test for significant differences between patient groups. Pairwise multiple comparison procedures (Student-Newman-Keuls method) were then used to confirm significant differences between specific patient groups. Pearson's moment correlations were used to test for correlations between nitrite levels and possible influencing factors such as age, family history of asthma and the number of known allergies, within each patient group. One-way ANOVA were used to test for differences between healthy subjects and differing levels of severity of asthma or $\mathrm{CF}$.

\section{Results}

Breath condensates could be obtained easily in all children, confirming that this test is suitable for children as young as 3 yrs of age. Figure 1 shows the median and percentile data for the differing patient groups. One-way ANOVA analysis showed highly significant differences in nitrite levels between the groups $(\mathrm{p}<0.001)$. Asthmatic (median: 5-95\% percentiles; 2.10: $0.63-5.45 \mu \mathrm{M})$ and $\mathrm{CF}$ (2.02: $0.43-6.37 \mu \mathrm{M})$ groups had significantly elevated nitrite when compared to the healthy $(0.41: 0.13-$ $1.83 \mu \mathrm{M})$ and episodic cough groups (0.75: $0.03-$ $1.75 \mu \mathrm{M} ; \mathrm{p}<0.05)$. No significant differences were

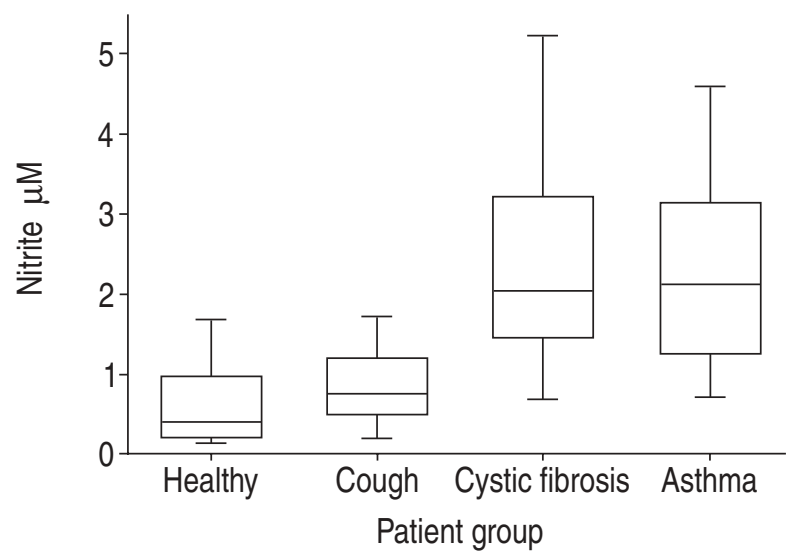

Fig. 1.-Nitrite levels in the exhaled condensate. The box plots are bounded by the 25 and $75 \%$ percentiles, with the horizontal line representing the median value. The whiskers denote the 10 and $90 \%$ percentile intervals. Asthmatic and cystic fibrosis patients exhibited significantly higher levels of nitrite than healthy children, and children with nonasthmatic, episodic cough $(\mathrm{p}<0.05)$. noted between the asthmatic and CF groups, nor the healthy and cough groups. Nitrite levels were not correlated with age, family history of asthma, antiinflammatory treatment nor the number of allergic sensitizations within any patient group. Children with mild (2.02: $0.53-5.06 \mu \mathrm{M})$ or moderate asthma (3.51: $1.66-5.45 \mu \mathrm{M})$ had significantly elevated nitrite concentrations compared to healthy subjects, but were not different from each other. Similarly, children with mild (2.16: $0.39-6.6 \mu \mathrm{M})$, moderate (1.87: $0.78-4.62 \mu \mathrm{M})$ and severe (2.13: $1.62-3.12 \mu \mathrm{M}) \mathrm{CF}$ had significantly elevated nitrite in the exhaled breath condensate, compared to healthy children regardless of disease severity (multiple pairwise comparisons; $\mathrm{p}<0.05)$.

\section{Discussion}

The present study assessed the nitrite levels in exhaled breath condensates of children. Nitrite was elevated in those children with asthma and CF, when compared to children with a history of obstructive cough, but not asthma, or children with no history of respiratory disease. Condensates could be easily collected in children as young as 3 yrs, suggesting this may be a highly useful, noninvasive method of assessing airway inflammation in this population. The levels of nitrite in the healthy control group of the present study were similar (median: range; 0.41: $0.13-1.87 \mu \mathrm{M})$ to those reported in healthy children [7] (range; 0-3.7 $\mu \mathrm{M})$, and by Ho et al. [6] (0.36:

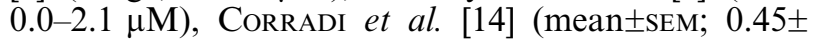
$0.06 \mu \mathrm{M})$, Hunt et al. $(0.78 \pm 0.072 \mu \mathrm{M})[15]$ and $(0.55$ : $0.31-2.33 \mu \mathrm{M})[16]$ in healthy adults, however the values were significantly lower than those reported by Nightingale et al. [17] $(1.8 \pm 0.3 \mu \mathrm{M}$; t-test: $\mathrm{p}<0.002)$.

While nitrites in exhaled condensates have not been reported in asthmatic children, a number of studies have reported nitrites in asthmatic adults, with conflicting results [14-17]. The London group [14, 17] found no significant elevation of nitrites in untreated, mild asthmatics, while demonstrating increased nitrite in severe, steroid-dependant asthmatics [14]. HunT et al. [16], demonstrated that the levels of eNO and nitrite were dependent on airway acidosis, demonstrating low airway $\mathrm{pH}$ levels in untreated asthmatics that returned to normal following inhaled corticosteroid treatment. Low $\mathrm{pH}$ acts to convert nitrite to NO, resulting in normal levels of nitrite in those asthmatics with low airway $\mathrm{pH}$ levels, while asthmatic subjects with normal airway $\mathrm{pH}$ had significantly elevated nitrite [16]. This study provides some explanation of the contrasting results reported in asthmatic adults [14, 17] and those children with asthma in the current study. No significant elevation of nitrite was found in untreated mild asthmatics, with significant increases in eNO [14, 17], while steroid-dependent patients with severe asthma exhibited significantly elevated nitrite $(1.04 \pm 0.19 \mu \mathrm{M})$ and eNO compared to healthy adults, and decreased eNO compared to mild asthmatics. This pattern of reversal of nitrite and eNO levels could be explained 
by alterations in airway $\mathrm{pH}$ following corticosteroid treatment.

The majority of asthmatic children in the present study were receiving inhaled corticosteroid treatment and did not have significantly different levels of nitrite compared to untreated asthmatic children. The role of airway acidosis in altering concentrations of eNO and nitrite has not been investigated in paediatric patients. The $\mathrm{pH}$ levels of exhaled breath condensates in the present study were not ascertained and further investigations are needed to determine the role of airway acidosis in paediatric asthma. Increased levels of nitrite and nitrate have been reported in the induced sputum of asthmatic adults and these were found to be correlated with a higher percentage of eosinophils and higher levels of eosinophil cationic protein [18]. Four patients within the asthmatic group had had recent symptoms of bronchial obstruction. These children tended to have higher concentrations of nitrites in the exhaled condensates when compared with the stable asthmatics. Unfortunately the number of patients presenting with acute exacerbation was too low to allow definitive conclusions to be drawn. However the trend observed is in agreement with the work of ARTLICH et al. [19], who demonstrated that eNO was related to clinical symptoms in asthmatic children.

The elevation of nitrites in the exhaled breath condensate of children with $\mathrm{CF}$ in the present study confirms the outcome of previous investigations [6, 7]. This elevation is thought to be due to the reduction of gaseous NO to it's metabolites, within the increased secretion barrier present in airways of CF patients. Ho et al. [6] demonstrated that, while eNO levels were normal in adult $\mathrm{CF}$ patients the levels of nitrites were elevated when compared to control subjects. These investigators also demonstrated that the nitrite levels were correlated to circulating levels of leukocytes and neutrophils, but not lung function.

Normal levels of eNO have been demonstrated in adult patients with nonasthmatic, chronic cough [20] supporting the results found in children with episodic cough in the present study. In addition, in a group of children with chronic cough, without wheeze, MARGUeT et al. [21] found no significant difference in cell profiles recovered from bronchoalveolar lavage samples in comparison to those recovered from healthy controls. In contrast, JATAKANON et al. [22] demonstrated an increased percentage of neutrophils and concentrations of tumour necrosis factor-alpha and interleukin- 8 in adult patients with nonasthmatic cough when compared to healthy controls. No differences were noted in macrophages, eosinophils or lymphocytes. The reasons for normal levels of NO or it's by-products in patients with nonasthmatic cough is not clear. It may be that patients with nonasthmatic cough are triggered by neural reflexes or by environmental factors, such as pollutants rather than by eosinophilic inflammation, which is known to be correlated to NO [18, 23]. Further, larger studies are warranted, but it may be that the measurement of NO metabolites would provide a useful diagnostic tool in those patients with cough, suspected of asthma, in whom more extensive studies cannot be carried out, such as young children.

\section{Limitations of the study}

While the present study was carried out without the assessment of salivary contamination, the apparatus did include a saliva trap. CunNingham et al. [7] have shown that while the contamination of samples with saliva may occur, this contamination has minimal effects on the results. Saturated exhaled breath originates from both the upper and lower airways [11]. The expiratory resistance $\left(4-5 \mathrm{cmH}_{2} \mathrm{O}\right)$ applied in the present study would be sufficient to close the vellum of the subjects, and hence the collected condensate and subsequently measured nitrite will reflect lower airway production. The subjects in the present study were recruited from a number of outpatient clinics and no attempt was made to match the groups for age, sex nor atopic status. There were significant differences in age between the subject groups (one-way ANOVA, $\mathrm{p}<0.001$ ), with the $\mathrm{CF}$ children being significantly older and the children with episodic cough being significantly younger than the remaining groups, while healthy and asthmatic children were not significantly different from each other in age. It is possible that these differences may have contributed to the reported differences in nitrites between the subject groups. However, nitrites were not significantly correlated to age within any subject group. These results are in agreement with those reported by CUNNINGHAM et al. [7] in children with CF and healthy controls, suggesting that the reported differences in nitrite were not related to differences in the ages of the subject groups. Similarly, no significant differences were found in nitrite concentrations between males and females in any group, suggesting sex differences between the groups did not play a role in presented results.

Atopy is known to influence eNO, both in asthmatic [24] and healthy [25] children. In the present study, atopy did not significantly influence nitrites in the exhaled breath condensate, within the cough or asthmatic groups. However the number of nonatopic subjects was low (two of 28 asthmatics, and three of seven coughers) and definitive conclusions cannot be drawn from this data set. While a standardized technique for the collection of eNO is now advocated in older children and adults [9, 10], younger children may not be able to produce the constant flow required for these methods or be able to produce sputum. Hence, condensates may be a simple noninvasive alternative within these patients in whom active cooperation cannot be obtained.

The metabolites of nitric oxide can be conveniently, cheaply and rapidly measured in breath condensates of children older than 3 yrs of age. As demonstrated in previous preliminary studies, nitrite levels were found to be significantly higher in patients with cystic fibrosis and in asthmatic subjects, when compared to the control group and to those patients with obstructive cough. Further studies are required to investigate the benefits of nitrites in exhaled 
condensates in discriminating between recurrent cough and asthma in young children.

Acknowledgements. The authors would like to thank S. Loeliger for her technical assistance with the nitrite assays.

\section{References}

1. Barnes PJ, Belvisi MG. Nitric oxide and lung disease. Thorax 1993; 48: 1034-1043.

2. Yates DH, Kharitonov SA, Robbins RA, Thomas PS, Barnes PJ. Effect of a nitric oxide synthase inhibitor and a glucocorticosteroid on exhaled nitric oxide. Am J Respir Crit Care Med 1995; 152: 892-896.

3. Hamid Q, Springall DR, Riveros-Moreno V, et al. Induction of nitric oxide synthase in asthma. Lancet 1993; 342: 1510-1513.

4. Grasemann H, Michler E, Wallot M, Ratjen F. Decreased concentration of exhaled nitric oxide (NO) in patients with cystic fibrosis. Pediatr Pulmonol 1997; 24: 173-177.

5. Linnane SJ, Keatings VM, Costello CM, et al. Total sputum nitrate plus nitrite is raised during acute pulmonary infection in cystic fibrosis. Am $J$ Respir Crit Care Med 1998; 158: 207-212.

6. Ho LP, Innes JA, Greening AP. Nitrite levels in breath condensate of patients with cystic fibrosis is elevated in contrast to exhaled nitric oxide. Thorax 1998; 53: 680-684.

7. Cunningham S, McColm JR, Ho LP, Greening AP, Marshall TG. Measurement of inflammatory markers in the breath condensate of children with cystic fibrosis. Eur Respir J 2000; 15: 955-957.

8. Baraldi E, Dario C, Ongaro R, et al. Exhaled nitric oxide concentrations during treatment of wheezing exacerbation in infants and young children. Am J Respir Crit Care Med 1999; 159: 1284-1288.

9. Kharitonov S, Alving K, Barnes PJ. Exhaled and nasal nitric oxide measurements: recommendations. The European Respiratory Society Task Force. Eur Respir J 1997; 10: 1683-1693.

10. Anonymous. Recommendations for standardized procedures for the online and offline measurement of exhaled lower respiratory nitric oxide and nasal nitric oxide in adults and children. Am J Respir Crit Care Med 1999; 160: 2104-2217.

11. Scheideler L, Manke HG, Schwulera U, Inacker O, Hammerle H. Detection of nonvolatile macromolecules in breath. A possible diagnostic tool? Am Rev Respir Dis 1993; 148: 778-784.

12. National Institutes of Health, National Heart, Lung and Blood Institute. International consensus report on diagnosis and treatment of asthma. National Institutes of Health. Bethesda, Maryland 20892. Publication no. 92-3091, March 1992. Eur Respir J 1992; 5: 601641.

13. Dohlman AW, Black HR, Royall JA. Expired breath hydrogen peroxide is a marker of acute airway inflammation in pediatric patients with asthma. Am Rev Respir Dis 1993; 148: 955-960.

14. Corradi M, Montuschi P, Donnelly LE, Pesci A, Kharitonov SA, Barnes PJB. Increased nitrosothiols in exhaled breath condensate in inflammatory airway disease. Am J Respir Crit Care Med 2001; 163: $854-$ 858.

15. Hunt J, Byrns RE, Ignarro LJ, Gaston B. Condensed expirate nitrite as a home marker for acute asthma. Lancet 1995; 346: 1235-1236.

16. Hunt JF, Fang K, Malik R, et al. Endogenous airway acidification. Implications for asthma pathophysiology. Am J Respir Crit Care Med 2000; 161: 694 699.

17. Nightingale JA, Rogers DF, Barnes PJ. Effect of inhaled ozone on exhaled nitric oxide, pulmonary function, and induced sputum in normal and asthmatic subjects. Thorax 1999; 54: 1061-1069.

18. Yang AS, Choi IS. Nitric oxide metabolites in patients with asthma: induced sputum versus blood. Respir Med 1999; 93: 912-918.

19. Artlich A, Busch T, Lewandowski K, Jonas S, Gortner L, Falke KJ. Childhood asthma: exhaled nitric oxide in relation to clinical symptoms. Eur Respir J 1999; 13: 1396-1401.

20. Chatkin JM, Ansarin K, Silkoff PE, et al. Exhaled nitric oxide as a noninvasive assessment of chronic cough. Am J Respir Crit Care Med 1999; 159: 18101813.

21. Marguet C, Jouen-Boedes F, Dean TP, Warner JO. Bronchoalveolar cell profiles in children with asthma, infantile wheeze, chronic cough, or cystic fibrosis. Am J Respir Crit Care Med 1999; 159: 1533-1540.

22. Jatakanon A, Lalloo UG, Lim S, Chung KF, Barnes PJ. Increased neutrophils and cytokines, TNF-alpha and IL-8, in induced sputum of non-asthmatic patients with chronic dry cough. Thorax 1999; 54: 234-237.

23. Chan-Yeung $M$, Obata $H$, Dittrick $M$, Chan $H$, Abboud R. Airway inflammation, exhaled nitric oxide, and severity of asthma in patients with western red cedar asthma. Am J Respir Crit Care Med 1999; 159: 1434-1438.

24. Frank TL, Adisesh A, Pickering AC, et al. Relationship between exhaled nitric oxide and childhood asthma. Am J Respir Crit Care Med 1998; 158: 1032-1036.

25. Franklin PJ, Taplin R, Stick SM. A community study of exhaled nitric oxide in healthy children. Am J Respir Crit Care Med 1999; 159: 69-73. 